\title{
Insulin-like growth factor 1 receptor expression in advanced non-small-cell lung cancer and its impact on overall survival
}

\author{
Mojca Humar'1, Izidor Kern², Gregor Vlacic², Vedran Hadzic³, Tanja Cufer² \\ ${ }^{1}$ General hospital of Nova Gorica, Šempeter Pri Gorici, Slovenia \\ 2 University Clinic Golnik, Golnik, Slovenia \\ ${ }^{3}$ Faculty of Sport, University of Ljubljana, Slovenia, Ljubljana, Slovenia
}

Radiol Oncol 2017; 51(2): 195-202.

Received 16 October 2016

Accepted 8 November 2016

Correspondence to: Mojca Humar, M.D., General Hospital of Nova Gorica, Ulica padlih borcev $13 a, 5290$ Šempeter pri Gorici, Slovenia. Phone: +386 5330 1000; Fax: +386 5330 1057; Email: moj.humar@gmail.com

Disclosure: No potential conflicts of interest were disclosed.

Background. The insulin-like growth factor 1 receptor (IGFIR) expression has been addressed as a potential prognostic marker in non-small-cell lung cancer (NSCLC) in various studies; however, the associations between IGFIR expression and prognosis of advanced NSCLC patients is still controversial. The aim of our observational, cohort study was to evaluate the expression of IGFIR in advanced NSCLC and its prognostic role. A subgroup analysis was performed to address the influence of pre-existing type 2 diabetes mellitus (T2DM) status on IGFIR expression and overall survival (OS).

Patients and methods. IGFIR expression was evaluated in 167 consecutive advanced NSCLC patients (stage IIIB and IV), diagnosed and treated at one university institution, between 2005 and 2010 . All patients received at least one line of standard cytotoxic therapy and 18 of them had pre-existing T2DM. IGFIR expression was determined by immunohistochemical (IHC) staining, with score $\geq 1+$ considered as positive. Information on baseline characteristics, as well as patients' follow-up data, were obtained from the hospital registry. Associations of IGFIR expression with clinical characteristics and overall survival were compared.

Results. IGFIR expression was positive in $79.6 \%$ of patients, significantly more often in squamous-cell carcinoma (SCC) compared to non-squamous-cell (NSCC) histology (88.7\% vs. 74.3\%; P = 0.03). IGF1R positivity did not correlate with T2DM status or with other clinical features (sex, smoking status, performance status). Median OS was similar between IGFIR positive and IGFIR negative group (10.2 vs. 8.5 months, $P=0.168$ ) and between patients with or without T2DM (8.7 vs. 9.8 months, $P=0.575$ ). Neither IGFIR expression nor T2DM were significant predictors of OS.

Conclusions. IGFIR or T2DM status were not significantly prognostic in described above collective of advanced NSCLC treated with at least one line of chemotherapy. In addition, no association between T2DM status and IGFIR expression was found. Further studies on IGFIR expression and its prognostic as well as therapeutic consequences in a larger collective of advanced NSCLC patients, with or without T2DM, are needed.

Key words: insulin-like growth factor 1 receptor; type 2 diabetes mellitus; advanced non-small-cell lung cancer; overall survival

\section{Introduction}

Lung cancer is the most common cancer diagnosed worldwide, and approximately $85 \%$ of cases represent non-small-cell lung cancer (NSCLC). ${ }^{1}$ Since lung cancer in the early stages is generally asymptomatic, almost two-thirds of patients are diagnosed in advanced stages. ${ }^{2,3}$ While patients with localized or locally advanced lung cancer have approximately $50 \%$ and $30 \%$ chance of five-year 
survival $^{4}$, advanced lung cancer is still incurable. Despite the rise in survival rates lately, five-year relative survival of patients with advanced lung carcinoma remains poor. ${ }^{4}$

Advances in recent survival rates are attributable to the discovery of potential targets such as mutations in the epidermal growth factor receptor (EGFR) or rearrangements in the anaplastic lymphoma kinase (ALK) gene and consecutive development of targeted therapies with monoclonal antibodies $(\mathrm{mAb})$ and tyrosine kinase inhibitors (TKI). ${ }^{5,6}$ However, although targeted therapies offer high objective response rates and improved progression-free survival (PFS), eventually acquired resistance develops, leading to disease progression. ${ }^{7}$ To overcome the resistance mechanisms new molecular alterations in different other co-activated pathways are extensively sought.

The insulin-like growth factor 1 receptor (IGF1R) signalling pathway has been shown to promote oncogenic transformation and cancer cell growth and survival ${ }^{8,9}$ and has been associated with resistance to specific oncologic therapies in various human cancers $^{10-12}$, including EGFR-TKI ${ }^{13,14}$ and ALK-TKI ${ }^{15}$ in NSCLC. With various lines of evidence supporting IGF1R signalling pathway as a potential target for cancer therapy, different anti-IGF1R $\mathrm{mAbs}$ and small-molecule TKIs were developed and entered clinical trials. However, despite the encouraging preclinical data, all the trials performed so far failed to confirm a meaningful clinical response in NSCLC patients treated with IGF1R inhibitors, although such results can be attributed to unselected patients, lack of predictive biomarkers and compensatory signalling through other growth factor pathways. ${ }^{16}$

IGF1R is a transmembrane heterotetrameric protein with tyrosine kinase activity. Binding of IGF1 and IGF2 activates the IGF1R, triggering a series of reactions via the PI3K-AKT and RAS/RAF/ mitogen-activated protein kinase signalling pathways, enhancing cancer cell growth, survival and metastasizing.

IGF1R and its signalling pathway were extensively studied in various human cancers. In hormone-receptor positive breast cancer (luminal A, luminal B) positive IGF1R expression is associated with better prognosis ${ }^{17,18}$, while in triple negative breast cancer it negatively affects survival. ${ }^{17,19}$ Similarly, IGF1R overexpression in laryngeal ${ }^{20}$, cervical $^{21}$, pancreatic ${ }^{22}$, gastric ${ }^{23}$, renal ${ }^{24}$ and urothelial carcinoma ${ }^{25}$ is linked to worse survival rates, whereas the influence of IGF1R overexpression on survival in colorectal and endometrial carcinoma remains unconfirmed. ${ }^{26-29}$

IGF1R expression was also addressed as a potential prognostic marker in NSCLC in various studies. ${ }^{14,30-47}$ Most of the studies involved patients with resected lung cancer and only four among them were performed in advanced NSCLC. 12,32,42,44 Cappuzzo et al. found that gefitinib-treated patients with high IGF1R overexpression had longer median survival ${ }^{44}$, while Yeo et al. reported a shorter progression-free survival in response to EGFRTKI in EGFR mutated patients ${ }^{14}$, while Kim et al. found no significant connection between IGF1R overexpression and survival of advanced NSCLC patients. ${ }^{46}$ Similar results were obtained in surgically treated NSCLC patients. ${ }^{30-33,35-42,45,47}$ In 2014 a meta-analysis including 17 studies evaluating IGF1R expression and its impact on survival in NSCLC patients was published, that confirmed the association between positive IGF1R expression and worse disease-free survival, but not OS. ${ }^{48}$ However, only three studies evaluated IGF1R expression in advanced NSCLC ${ }^{34,44,46}$, and a subgroup analysis of two of them ${ }^{44,46}$, including 77 and 68 patients respectively, showed a significant correlation between IGF1R expression and better OS.

Moreover, optimal evaluation of IGF1R expression remains unconfirmed. In most of the published studies in NSCLC IGF1R protein expression was measured by immunohistochemistry, while some also evaluated IGF1R gene expression using quantitative reverse transcription polymerase chain reaction (qRT-PCR) and IGF1R gene copy number by in situ hybridization. In summary, scarce and conflicting information exist concerning IGF1R expression impact on survival in advanced NSCLC.

There are epidemiological data supporting the biological link between cancer and type 2 diabetes mellitus (T2DM) and the well-known fact that patients with T2DM have an increased risk of cancer and cancer-related mortality. ${ }^{49}$ In a recently published study, a higher IGF1R expression - according to the previously mentioned meta-analysis a detrimental prognostic factor in operable NSCLC was found in early stage NSCLC patients with preexisting T2DM, suggesting a possible role of IGF1R signalling pathway in the development and growth of NSCLC. ${ }^{50}$ Type 2 diabetes mellitus is characterized by insulin resistance and resultant chronic hyperinsulinemia, which enhances growth hormone receptor expression in the liver, increases IGF1 production and availability, thus leading to the IGF1R signalling pathway activation. ${ }^{51,52}$ Several meta- 
analyses and studies have been published in the recent years, confirming diabetes mellitus as a negative prognostic factor for breast, colorectal, gastric, pancreatic, liver, prostate, renal and cervical cancer survival. ${ }^{53-60}$ Studies addressing the prognostic role of T2DM in NSCLC patients have been contradictory ${ }^{61-63}$ However, the recently published meta-analysis confirmed a significant association between T2DM and worse prognosis in NSCLC patients, especially in surgically treated patients. ${ }^{64}$ There are also data showing that the use of metformin, one of the most commonly prescribed drugs for diabetes mellitus, improves the generally bad prognosis of cancer patients with concomitant T2DM. In a large meta-analysis, the use of metformin was associated with a significant improvement in overall survival and cancer-specific survival of cancer patients. ${ }^{65}$

The purpose of this study was to evaluate IGF1R expression in advanced NSCLC and its impact on OS. Furthermore, we evaluated the influence of T2DM on OS and IGF1R expression in advanced NSCLC.

\section{Patients and methods}

Our study was performed following the Recommendations for Tumour Marker Prognostic Studies (REMARK). ${ }^{66}$

\section{Patient selection}

In the present study 167 consecutive patients, with patohistologically confirmed advanced NSCLC stage IIIB (20 patients) and IV (147 patients), treated with at least one line of cytotoxic therapy at the University Clinic Golnik, Slovenia, between 2005 and 2010, and with available tissue for immunohistochemical analysis, were included. All patients were treated and followed according to the standard clinical practices at the time. All patients received at least one systemic treatment, that comprised of platinum doublets in a vast majority of them (165/167 patients; $98.8 \%)$, only two patients $(1.2 \%)$ received gemcitabine monotherapy. The median follow-up time was 9.79 months (range 0.20-72.34 months).

Information on baseline demographics and clinicopathological characteristics of the patients were obtained from our hospital registry system, whilst date of death was obtained from the National Cancer Registry.

The study was reviewed and approved by the National Ethics Committee (No. 135/07/09).

\section{Tissue preparation and immunohistochemical analysis}

Formalin-fixed, paraffin-embedded tissue sections containing preserved tumour tissue from primary tumour obtained at diagnosis were used for immunohistochemical analysis.

Tissue sections $4-\mu \mathrm{m}$ thick were deparaffinized in xylene and rehydrated in a graded series ethanol. After standard antigen retrieval with Cell Conditioning 1 (CC1) buffer solution (Ventana Medical Systems, Tucson, Arizona, USA), staining with pre-diluted rabbit monoclonal antibody against human IGFR-1 (Ventana G11; CONFIRM, Ventana Medical Systems, Tucson, Arizona, USA; ready-to-use concentration $1.7 \mu \mathrm{g} / \mathrm{mL}$ ) was performed on Ventana BenchMark XT autostainer with a 16 minutes primary antibody incubation time at $37^{\circ} \mathrm{C}$. Binding detection of the primary antibody was performed utilizing the ultraView Universal DAB Detection Kit (Ventana Medical Systems, Tucson, Arizona, USA), and subsequently, the slides were counterstained with Hematoxylin II (Ventana Medical Systems, Tucson, Arizona, USA), according to the manufacturers' recommendations. The omission of the primary antibody was used as a negative control. IGF1R expression in adjoining normalappearing bronchial epithelium within each tissue section was used as an internal positive control.

Immunohistochemical (IHC) staining of the invasive cancer components was independently evaluated on at least $2 \times 2 \mathrm{~mm}$ cores per patient by two observers (MH, GV), blinded to all patient data. Discrepant cases were reviewed by a third observer (IK). Cell membrane and cytoplasm staining was scored on a scale of 0 (no staining), 1+ (weak staining), 2+ (moderate staining), and 3+ (strongly positive staining). Since there are no validated and standardized cut-off values for IGF1R-IHC positivity, membrane staining equal or above $1+$ in at least $1 \%$ of tumour cells was considered positive.

\section{Statistical analysis}

Associations of IGF1R expression with patient clinical characteristics were compared by chi-square test. OS (time in months from diagnosis date to patient death) was evaluated using Kaplan-Meier method and hazard ratio was calculated by using the Cox proportional hazards regression model. OS for the subgroups was compared using the logrank test.

Statistical analysis was performed using IBM SPSS ver. 19.0 (SPSS Inc., Chicago, IL, USA). A 
TABLE 1. Patient and tumour characteristics

\begin{tabular}{lc}
\hline Variable & No (\%) \\
\hline All patients & $167(100 \%)$ \\
Histology & \\
- NSCC & $105(62.9 \%)$ \\
- SCC & $62(37.1 \%)$ \\
Sex & \\
- Male & $119(71.3 \%)$ \\
- Female & $48(28.7 \%)$ \\
Smoking status & \\
-Current/former smoker & $145(86.8 \%)$ \\
- Never smoker & $22(13.2 \%)$ \\
ECOG-PS & \\
- 0-1 & $152(91.0 \%)$ \\
- $\geq 2$ & $15(9.0 \%)$ \\
Diabetes mellitus type 2 & \\
- No & $149(89.2 \%)$ \\
- Yes & $18(10.8 \%)$ \\
IGF1R expression & \\
- Positive & $133(79.6 \%)$ \\
- Negative & $34(20.4 \%)$ \\
\hline
\end{tabular}

ECOG-PS = Eastern Cooperative Oncology Group performance status: IGFIR = insulin-like growth factor-1 receptor; NSCC = non-squamous cel carcinoma; $S C C$ = squamous cell carcinoma

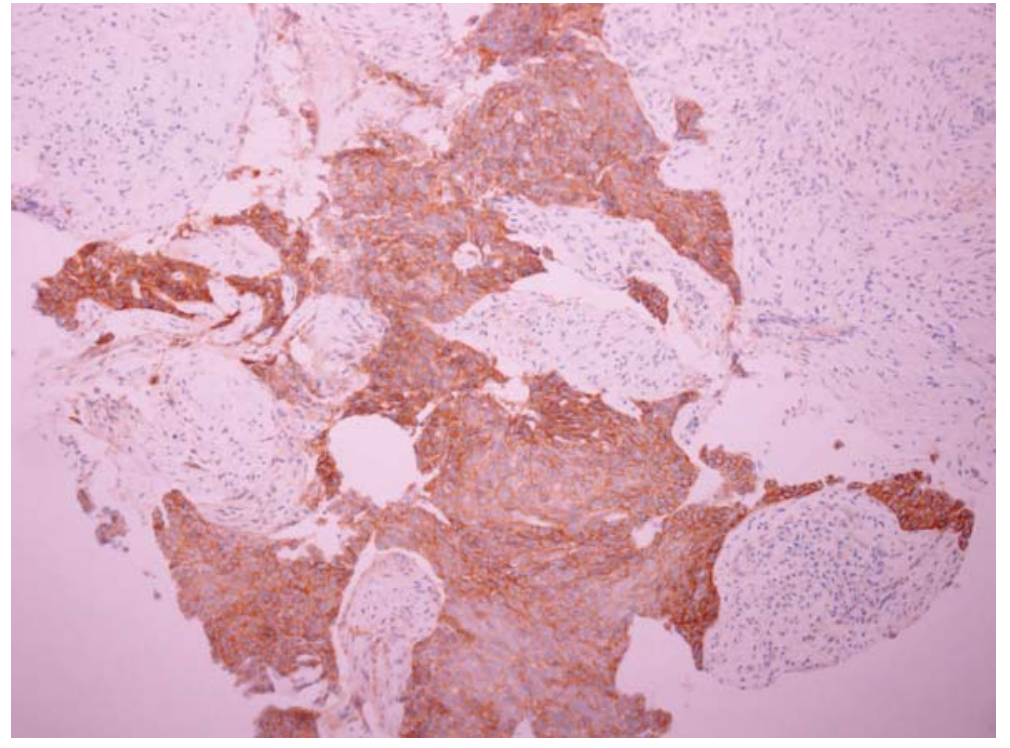

FIGURE 1. Representative immunohistochemical staining of insulin-like growth factor 1 receptor in a squamous-cell carcinoma sample.
$P$-value less than 0.05 was determined as statistically significant. All reported $P$-values are twotailed.

\section{Results}

\section{Patient and tumour characteristics}

A total of 167 patients were included in this study. Baseline demographics and clinicopathological characteristics are summarized in Table 1. At the time of diagnosis, median age was 63 years (range $40-82$ years), $37.1 \%$ of cases were squamous-cell carcinoma (SCC; 62/167 patients) and $62.9 \%$ were non-squamous-cell (NSCC; 105/167 patients) histology. The majority of patients were males $(119 / 167 ; 71.3 \%)$, smokers or former smokers $(145 / 167 ; 86.8 \%)$ and had an estimated Eastern Cooperative Oncology Group (ECOG) performance status of $0-1$ (152/167; 91.0\%). Pre-existing T2DM was present in 18 (10.8\%) of patients; 8 out of 18 were receiving metformin, while the rest of them were treated with other oral antidiabetic medications or insulin.

\section{IGF1R expression}

IGF1R expression was found in 133/167 (79.6\%) of tumour samples. IGF1R positivity was significantly more frequent in SCC $(88.7 \%)$ compared to NSCC $(74.3 \%)(P=0.03)$ (Figure 1). However, there was no significant association between IGF1R positivity rate and sex, smoking status, performance status or T2DM (Table 2). The IGF1R positivity rate was quite similar in patients with or without T2DM; $77.8 \%$ and $79.9 \%$, respectively.

\section{Survival analysis}

Median OS was similar between IGF1R positive and IGF1R negative group (10.2 versus 8.5 months, $P=0.168$ ) (Figure 2) and also between patients with or without T2DM (8.7 versus 9.8 months, $P=0.575$ ) (Figure 3).

Neither IGF1R expression nor T2DM were significant predictors of overall survival in the univariate and multivariate analysis. Regarding the other characteristics included in the analysis, no significant differences in survival were observed based on histology, whereas sex, smoking status and performance status were borderline significant in the univariate analysis, but in multivariate analysis only performance status remained borderline significant $(P=0.057)$ (Table 3$)$. 


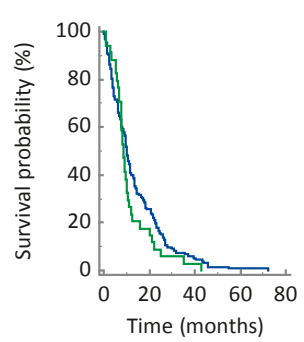

Number at risk

Group: IGF1R IHC POSITIVE $\begin{array}{lllll}133 & 34 & 7 & 1 & 0\end{array}$ Group: IGF1R IHC NEGATIVE

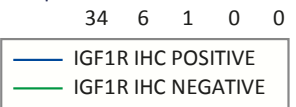

FIGURE 2. Median overall survival based on insulin-like growth factor 1 receptor (IGFIR) expression.

\section{Discussion}

In the present study, we aimed to assess the prognostic impact of IGF1R expression in 167 advanced NSCLC patients treated with at least one line of chemotherapy, and to evaluate the impact of T2DM on IGF1R expression, as well as its prognostic role. Neither IGF1R expression nor T2DM status were found to be independent predictors of OS in advanced NSCLC in the multivariate analysis of survival. In addition, no association between T2DM status and IGF1R expression was found. However,
TABLE 2. IHC IGFIR expression by histological/clinical characteristics and diabetes mellitus

\begin{tabular}{lccc}
\hline Variable & $\begin{array}{c}\text { IGF1R positive } \\
\text { No (\%) }\end{array}$ & $\begin{array}{c}\text { IGF1R negative } \\
\text { No (\%) }\end{array}$ & P value \\
\hline All patients & $133(79.6 \%)$ & $34(20.4 \%)$ & \\
Histology & $78(74.3 \%)$ & $27(25.7 \%)$ & 0.03 \\
- NSCC & $55(88.7 \%)$ & $7(11.3 \%)$ & \\
- SCC & & & 0.17 \\
Sex & $98(82.4 \%)$ & $21(17.6 \%)$ & \\
- Male & $35(72.9 \%)$ & $13(27.1 \%)$ & 0.77 \\
- Female & & & \\
Smoking status & $116(80.0 \%)$ & $29(20.0 \%)$ & \\
- Current/former smoker & $17(77.3 \%)$ & $5(22.7 \%)$ & \\
- Never smoker & & & 0.97 \\
ECOG - PS & $121(79.6 \%)$ & $31(20.4 \%)$ & \\
- O-1 & $12(80.0 \%)$ & $3(20.0 \%)$ & \\
- $\geq 2$ & & & \\
Diabetes mellitus type 2 & $119(79.9 \%)$ & $30(20.1 \%)$ & \\
- No & $14(77.8 \%)$ & $4(22.2 \%)$ & \\
- Yes & & & \\
\hline
\end{tabular}

ECOG-PS = Eastern Cooperative Oncology Group performance status; IGFIR = insulin-like growth factor-1 receptor; NSCC = non-squamous cell carcinoma; SCC = squamous cell carcinoma

a significantly higher expression of IGF1R in SCC compared to NSCC histology was observed.

Interestingly, a significant association between positive IGF1R expression and SCC histology was

TABLE 3. Univariate and multivariate analysis of overall survival

\begin{tabular}{|c|c|c|c|c|c|c|}
\hline \multirow{2}{*}{ Variable } & \multicolumn{3}{|c|}{ Univariate Analysis } & \multicolumn{3}{|c|}{ Multivariate Analysis } \\
\hline & $\mathrm{HR}$ & $95 \% \mathrm{Cl}$ & $P$ value & $\mathrm{HR}$ & $95 \% \mathrm{Cl}$ & $P$ value \\
\hline \multicolumn{7}{|l|}{ Histology } \\
\hline SCC vs NSCC & 1.097 & $0.798-1.509$ & 0.569 & 1.249 & $0.885-1.763$ & 0.206 \\
\hline \multicolumn{7}{|l|}{ Sex } \\
\hline Male vs female & 1.396 & $0.994-1.961$ & 0.054 & 1.390 & $0.939-2.057$ & 0.100 \\
\hline \multicolumn{7}{|l|}{ Smoking status } \\
\hline $\begin{array}{l}\text { Current/former smoker vs. } \\
\text { non-smoker }\end{array}$ & 1.692 & $1.064-2.689$ & 0.026 & 1.509 & $0.908-2.510$ & 0.113 \\
\hline \multicolumn{7}{|l|}{ ECOG-PS } \\
\hline $0-1$ vs $\geq 2$ & 0.600 & $0.351-1.025$ & 0.061 & 0.589 & $0.341-1.015$ & 0.057 \\
\hline \multicolumn{7}{|l|}{ Diabetes mellitus type 2} \\
\hline Yes vs No & 0.869 & $0.531-1.423$ & 0.576 & 0.828 & $0.498-1.378$ & 0.468 \\
\hline \multicolumn{7}{|l|}{ IGF1R } \\
\hline Positive vs negative & 0.766 & $0.523-1.121$ & 0.170 & 0.776 & $0.518-1.162$ & 0.219 \\
\hline
\end{tabular}

ECOG-PS = Eastern Cooperative Oncology Group performance status; IGFIR = insulin-like growth factor-1 receptor; NSCC = non-squamous cell carcinoma; SCC = squamous cell carcinoma 
observed in our study $(P=0.03)$, that is in line with the data from the meta-analysis of Zhao et al., where a trend towards an increased IGF1R expression in SCC histology was noted. ${ }^{48}$ However, only 10 out of 17 included studies (46\% of included patients) had sufficient data to assess the relationship between IGF1R expression and histology. In addition, in advanced NSCLC Kim et al. found a significantly higher IGF1R expression in the SCC subgroup. ${ }^{46}$ Although the molecular basis of IGF1R overexpression in SCC remains unknown, these data suggest IGF1R expression might reflect an important role of the IGF1R signalling pathway in SCC development and spread.

No significant associations were noted between IGF1R expression and sex, smoking status and performance status in our study. Similarly, other published studies in advanced NSCLC did not report an association between IGF1R expression and the aforementioned prognostic factors ${ }^{14,34,44}$, with the exception of the study by Kim et al., where IGF1R expression was associated with smoking status ${ }^{46}$, in accordance to the meta-analysis. ${ }^{48}$ Whether this is a consequence of an underlying molecular mechanism, or the result of the majority of NSCLC patients being smokers, remains to be elucidated.

Although the OS of IGF1R positive patients with advanced NSCLC was longer than OS to IGF1R negative counterparts (10.2 vs. 8.5 months, $\mathrm{P}=0.168)$, this difference was not statistically significant. The trend shown in our study is consistent with the subgroup analysis in the meta-analysis, where IGF1R positive expression was associated with significantly better OS in NSCLC stage III and IV patients ${ }^{48}$, proposing that aberrant signalling pathways, other than IGF1R, take over the major role in advanced NSCLC progression.

Despite the increasing evidence that T2DM negatively affects cancer prognosis ${ }^{49,53-61,63,64}$, we could not prove a significant influence of T2DM on advanced NSCLC survival. Besides a relatively small proportion of patients with T2DM in our study (N $=18 ; 10.8 \%$ ), another confounding factor might be the fact, that almost half of our patients with T2DM were treated with metformin, known to improve cancer prognosis. ${ }^{65}$ Furthermore, IGF1R was not overexpressed in T2DM patients, compared to non-T2DM patients, opposing findings of Ding et al. who found higher IGF1R expression in patients with T2DM, compared to non-T2DM patients. ${ }^{50}$ However, as our T2DM subgroup was underpowered, our results need further confirmation on a larger group of patients with advanced NSCLC and T2DM.
In the present study, IGF1R expression was determined by immunohistochemistry, with an arbitrarily predefined cut-off value of $\geq 1+$. To emphasise, there are no validated scoring systems or cut-off values for IGF1R expression available, and in the published studies different thresholds were used, resulting in great differences in the percentage of positive samples (range $12.7 \%$ to $78.0 \%$ ). ${ }^{14,30-}$ ${ }^{45}$ Moreover, Dziadziuszko et al. reported that different anti-IGF1R antibodies on the market have different specificity to IGF1R. ${ }^{30}$ In summary, methodological issues might have a strong influence on IGF1R expression evaluation and the need for a validated system for IGF1R expression detection is warranted.

The major limitation of our study is the retrospective design and a relatively small number of advanced NSCLC patients included, especially patients with T2DM, affecting statistical power of survival analysis and accuracy of the findings. In addition, no validated scoring system for immunohistochemical IGF1R expression and an arbitrarily defined cut-off value for IGF1R positivity may be another source of bias. Unfortunately, in all of the studies addressing the prognostic role of IGF1R expression in advanced NSCLC the same limitations arise. ${ }^{14,34,44,46}$ Furthermore, tissue samples retrieved in NSCLC are often scanty, with small biopsies failing to show any intra-tumoural biomarker heterogeneity.

In conclusion, we did not confirm a prognostic value of IGF1R overexpression or T2DM in advanced NSCLC patients, treated with at least one line of chemotherapy. In spite of those negative findings in relation to IGF1R overexpression, we have shown a significant association between IGF1R and SCC, indicating a possible oncogenic role of IGF1R in SCC that deserves a further research. Yet, based on a small number of patients in our study, further prospective studies on IGF1R expression and its prognostic as well as therapeutic consequences in a larger collective of advanced NSCLC patients, with or without T2DM, are needed.

\section{Acknowledgements}

The authors thank Tončka Urbanc and Mitja Rot for help with tissue sections preparation and immunohistochemistry. This work was funded by Slovenian Research Agency Grant J3-4076. 


\section{References}

1. International Agency for Research on Cancer. World health Organization. GLOBOCAN 2012: estimated cancer incidence, mortality and prevalence worldwide in 20012. Lung cancer fact sheet. [Citated 2016 Jun 15]. Available at http://globocan.iarc.fr/Pages/fact_sheets_cancer.aspx?cancer=lung.

2. Morgensztern D, Ng SH, Gao F, Govindan R. Trends in stage distribution for patients with non-small cell lung cancer: A National Cancer Database survey. J Thorac Oncol 2010; 5: 29-33. doi: 10.1097/JTO.0b013e3181c5920c

3. Debevec $L$, Jerič $T$, Kovač $V$, Bitenc $M$, Sok $M$. Is there any progress in routine management of lung cancer patients? A comparative analysis of an institution in 1996 and 2006. Radiol Oncol 2009; 43: 47-53. doi: 10.2478/v10019009-0008-x

4. Howlader N, Noone AM, Krapcho M, Miller D, Bishop K, Altekruse SF, et al. SEER cancer statistics review, 1975-2013. Bethesda: National Cancer Institute. [Citated 2016 Sept 04]. Available at http://seer.cancer.gov/ csr/1975_2013/

5. Sechler M, Cizmic AD, Avasarala S, Van Scoyk M, Brzezinski C, Kelley N, et al. Non-small-cell lung cancer: molecular targeted therapy and personalized medicine - drug resistance, mechanisms, and strategies. Pharmgenomics Pers Med 2013; 6: 25-36. doi: 10.2147/PGPM.S26058

6. Zwitter M, Stanic K, Rajer M, Kern I, Vrankar M, Edelbaher N, Kovac V. Intercalated chemotherapy and erlotinib for advanced NSCLC: high proportion of complete remissions and prolonged progression-free survival among patients with EGFR activating mutations. Radiol Oncol 2014; 48: 361-8. doi: 10.2478/raon-2014-0038

7. Wang J, Wang B, Chu H, Yao Y. Intrinsic resistance to EGFR tyrosine kinase inhibitors in advanced non-small-cell lung cancer with activating EGFR mutations. Onco Targets Ther 2016; 9: 3711-26. doi: 10.2147/OTT.S106399

8. Ward CW, Garrett TP, McKern NM, Lou M, Cosgrove $\sqcup$, Sparrow LG, et al. The three dimensional structure of the type I insulin-like growth factor receptor. Mol Pathol 2001; 54: 125-32.

9. Blakesley VA, Stannard BS, Kalebic T, Helman L, LeRoith D. Role of the IGF-I receptor in mutagenesis and tumor promotion. J Endocrinol 1997; 152: 33944.

10. Eckstein N, Servan K, Hildebrandt B, Politz A, von Jonquières G, WolfKümmeth $S$, et al. Hyperactivation of the insulin-like growth factor receptor I signalling pathway is an essential event for cisplatin resistance of ovarian cancer cells. Cancer Res 2009; 69: 2996-3003. doi: 10.1158/0008-5472.CAN08-3153

11. Huang $F, X u L A$, Khambata-Ford $S$. Correlation between gene expression of IGF-1R pathway markers and cetuximab benefit in metastatic colorectal cancer. Clin Cancer Res 2012; 18: 1156-66. doi: 10.1158/1078-0432.CCR-111135

12. Yuen JS, Akkaya E, Wang Y, Takiguchi M, Peak S, Sullivan M, et al. Validation of the type 1 insulin-like growth factor receptor as a therapeutic target in renal cancer. Mol Cancer Ther 2009; 8: 1448-59. doi: 10.1158/1535-7163. MCT-09-0101

13. Suda K, Mizuuchi H, Sato K, Takemoto T, Iwasaki T, Mitsudomi T. The insulinlike growth factor 1 receptor causes acquired resistance to erlotinib in lung cancer cells with the wild-type epidermal growth factor receptor. Int J Cancer 2014; 135: 1002-6. doi: 10.1002/ijc.28737

14. Yeo CD, Park KH, Park CK, Lee SH, Kim SJ, Yoon HK, et al. Expression of insulin-like growth factor 1 receptor (IGF-1R) predicts poor responses to epidermal growth factor receptor (EGFR) tyrosine kinase inhibitors in nonsmall cell lung cancer patients harboring activating EGFR mutations. Lung Cancer 2015; 87: 311-7. doi: 10.1016/j.lungcan.2015.01.004

15. Lovly CM, McDonald NT, Chen H, Ortiz-Cuaran S, Heukamp LC, Yan Y, et al. Rationale for co-targeting IGF1R and ALK in ALK fusion-positive lung cancer. Nat Med 2014; 20: 1027-34. doi: 10.1038/nm.3667

16. Beckwith $\mathrm{H}$, Yee D. Minireview: Were the IGF signaling inhibitors all bad? Mol Endocrinol 2015; 29: 1549-57. doi: 10.1210/me.2015-1157.

17. Yerushalmi R, Gelmon KA, Leung S, Gao D, Cheang M, Pollak M, et al. Insulinlike growth factor receptor (IGF-1R) in breast cancer subtypes. Breast Cancer Res Treat 2012; 132: 131-42. doi: 10.1007/s10549-011-1529-8
18. Mountzios G, Aivazi D, Kostopoulos I, Kourea HP, Kouvatseas G, Timotheadou $\mathrm{E}$, et al. Differential expression of the insulin-like growth factor receptor among early breast cancer subtypes. PLoS One 2014; 9: e91407. doi: 10.1371/journal.pone.0091407

19. Bahhnassy A, Mohanad M, Shaarawy S, Ismail MF, El-Bastawisy A, Ashmawy $A M$, et al. Transforming growth factor- $\beta$, insulin-like growth factor $1 /$ insulinlike growth factor I receptor and vascular endothelial growth factor-A: prognostic and predictive markers in triple-negative and non-triple-negative breast cancer. Mol Med Rep 2015; 12: 851-64. doi: 10.3892/mmr.2015.3560

20. Mountzios G, Kostopoulos I, Kotoula V, Sfakianaki I, Fountzilas E, Markou K, et al. Insulin-like growth factor 1 receptor (IGF1R) expression and survival in operable squamous-cell laryngeal cancer. PLoS One 2013; 8: e54048. doi: 10.1371/journal.pone.0054048

21. Huang Y-F, Shen M-R, Hsu K-F, Cheng Y-M, Chou C-Y. Clinical implications of insulin-like growth factor 1 system in early-stage cervical cancer. Br J Cancer 2008; 99: 1096-102. doi: 10.1038/sj.bjc.6604661

22. Hirakawa $T$, Yashiro M, Murata A, Hirata K, Kimura K, Amano R, et al. IGF-1 receptor and IGF binding protein-3 might predict prognosis of patients with resectable pancreatic cancer. BMC Cancer. 2013; 13: 392. doi: 10.1186/1471-2407-13-392

23. Numata K, Oshima T, Sakamaki K, Yoshihara K, Aoyama T, Hayashi T, et al. Clinical significance of IGF1R gene expression in patients with Stage II/III gastric cancer who receive curative surgery and adjuvant chemotherapy with S-1. J Cancer Res Clin Oncol 2016; 142: 415-22. doi: 10.1007/s00432015-2039-6

24. Sichani MM, Yazdi FS, Moghaddam NA, Chehrei A, Kabiri M, Naeimi A, et al. Prognostic value of insulin-like growth factor-I receptor expression in renal cell carcinoma. Saudi J Kidney Dis Transpl 2010; 21: 69-74.

25. Gonzalez-Roibon N, Kim JJ, Faraj SF, Chaux A, Bezerra SM, Munari E, et al. Insulin-like growth factor-1 receptor overexpression is associated with outcome in invasive urothelialcarcinoma of urinary bladder: a retrospective study of patients treated using radical cystectomy. Urology 2014; 83: 1444. e1-6. doi: 10.1016/j.urology.2014.01.028

26. Cappuzzo F, Varella-Garcia M, Finocchiaro G, Skokan M, Gajapathy S, Carnaghi $C$, et al. Primary resistance to cetuximab therapy in EGFR FISHpositive colorectal cancer patients. Br J Cancer 2008; 99: 83-9. doi: 10.1038/ sj.bjc. 6604439

27. Takahari D, Yamada Y, Okita N, T, Honda T, Hirashima Y, Matsubara J, et al Relationships of insulin-like growth factor-1 receptor and epidermal growth factor receptor expression to clinical outcomes in patients with colorectal cancer. Oncology 2009; 76: 42-8. doi: 10.1159/000178164

28. Joehlin-Price AS, Stephens JA, Zhang J, Backes FJ, Cohn DE, Suarez AA Endometrial cancer insulin-like growth factor 1 receptor (IGF1R) expression increases with body mass index and is associated with pathologic extent and prognosis. Cancer Epidemiol Biomarkers Prev 2016; 25: 438-45. doi: 10.1158/1055-9965.EPI-15-1145

29. Peiró G, Lohse P, Mayr D, Diebold J. Insulin-like growth factor-I receptor and PTEN protein expression in endometrial carcinoma. Correlation with bax and bcl-2 expression, microsatellite instability status, and outcome. Am J Clin Pathol 2003; 120: 78-85. doi: 10.1309/C1KA-H1PR-L1UB-W798

30. Dziadziuszko R, Merrick DT, Witta SE, Mendoza AD, Szostakiewicz B, Szymanowska A, et al. Insulin-like growth factor receptor 1 (IGF1R) gene copy number is associated with survival in operable non-small-cell lung cancer: a comparison between IGF1R fluorescent in situ hybridization, protein expression, and mRNA expression. J Clin Oncol 2010; 28: 2174-80. doi: 10.1200/JCO.2009.24.6611

31. Lee CY, Jeon JH, Kim HJ, Shin DH, Roh TW, Ahn CM, et al. Clinical significance of insulin-like growth factor-1 receptor expression in stage I non-small-cell lung cancer: immunohistochemical analysis. Korean J Intern Med 2008; 23: 116-20. doi: 10.3904/kjim.2008.23.3.116

32. Gong Y, Yao E, Shen R, Goel A, Arcila M, Teruya-Feldstein J, et al. High expression levels of total IGF-1R and sensitivity of NSCLC cells in vitro to an antiIGF-1R antibody (R1507). PLoS One 2009; 4: e7273. doi: 10.1371/journal. pone.0007273

33. Cappuzzo F, Tallini G, Finocchiaro G, Wilson RS, Ligorio C, Giordano L, et al. Insulin-like growth factor receptor 1 (IGF1R) expression and survival in surgically resected non-small-cell lung cancer (NSCLC) patients. Ann Oncol 2010; 21: 562-7. doi: 10.1093/annonc/mdp357 
34. Ning $\mathrm{XH}$, Wang YZ, Bai CM, Li J. Clinical significance of insulin-like growth factor-1 receptor in platinum-based chemotherapy for non-small celllung cancer. [Chinese]. Zhongguo Yi Xue Ke Xue Yuan Xue Bao 2010; 32: 366-70. doi: 10.3881/j.issn.1000-503X.2010.04.002

35. Tsuta K, Mimae T, Nitta H, Yoshida A, Maeshima AM, Asamura H, et al. Insulin-like growth factor-1 receptor protein expression and gene copy number alterations in non-small cell lungcarcinomas. Hum Pathol 2013; 44: 975-82. doi: 10.1016/j.humpath.2012.09.002

36. Ludovini V, Flacco A, Bianconi F, Ragusa M, Vannucci J, Bellezza G, et al. Concomitant high gene copy number and protein overexpression of IGF1R and EGFR negatively affect disease-free survival of surgically resected nonsmall-cell-lung cancer patients. Cancer Chemother Pharmacol 2013; 71: 671-80. doi: 10.1007/s00280-012-2056-y

37. Zhang $\mathrm{X}$, Sun J, Wang $\mathrm{H}$, Lou $\mathrm{Y}$, Zhang $\mathrm{Y}$, Sha $\mathrm{H}$, et al. IGF-1R and Bmi-1 expressions in lung adenocarcinoma and their clinicopathologic and prog nostic significance. Tumour Biol 2014; 35: 739-45. doi: 10.1007/s13277-013 $1100-9$

38. Gately K, Forde L, Cuffe S, Cummins R, Kay EW, Feuerhake F, et al. High coexpression of both EGFR and IGF1R correlates with poor patient prognosis in resected non-small-cell lung cancer. Clin Lung Cancer 2014; 15: 58-66. doi: 10.1016/j.cllc.2013.08.005

39. Tran TN, Selinger Cl, Yu B, Ng CC, Kohonen-Corish MR, McCaughan B, et al Alterations of insulin-like growth factor-1 receptor gene copy number and protein expression are common in non-small cell lung cancer. J Clin Pathol 2014; 67: 985-91. doi: 10.1136/jclinpath-2014-202347

40. Nakagawa M, Uramoto H, Shimokawa H, Onitsuka T, Hanagiri T, Tanaka F. Insulin-like growth factor receptor-1 expression predicts postoperative recurrence in adenocarcinoma of the lung. Exp Ther Med 2011; 2: 585-90. doi: $10.3892 /$ etm.2011.258

41. Kim JS, Kim ES, Liu D, Lee JJ, Solis L, Behrens C, et al. Prognostic impact of insulin receptor expression on survival of patients with non small cell lung cancer. Cancer 2012; 118: 2454-65. doi: 10.1002/cncr.26492

42. Yamamoto T, Oshima T, Yoshihara K, Nishi T, Arai H, Inui K, et al. Clinical significance of immunohistochemical expression of insulin-like growth factor-1 receptor and matrixmetalloproteinase-7 in resected non-small cell lung cancer. Exp Ther Med 2012; 3: 797-802. doi: 10.3892/etm.2012.493

43. Xu C, Xie D, Yu SC, Yang XJ, He LR, Yang J, et al. $\beta$-Catenin/POU5F1/SOX2 transcription factor complex mediates IGF-I receptor signaling and predicts poor prognosis in lung adenocarcinoma. Cancer Res 2013; 73: 3181-9. doi: 10.1158/0008-5472.CAN-12-4403

44. Cappuzzo F, Toschi L, Tallini G, Ceresoli GL, Domenichini I, Bartolini S, et al Insulin-like growth factor receptor 1 (IGFR-1) is significantly associated with longer survival in non-small-cell lung cancer patients treated with gefitinib. Ann Oncol 2006; 17: 1120-7. doi: 10.1093/annonc/mdl077

45. Kikuchi R, Sonobe M, Kobayashi M, Ishikawa M, Kitamura J, Nakayama E, et al. Expression of IGF1R is associated with tumor differentiation and survival in patients with lung adenocarcinoma. Ann Surg Oncol 2012; 19(Suppl 3): S412-20. doi: 10.1245/s10434-011-1878-x.

46. Kim YH, Sumiyoshi S, Hashimoto S, Masago K, Togashi $Y$, Sakamori Y, et al. Expressions of insulin-like growth factor receptor-1 and insulin-like growth factor binding protein 3 in advanced non-small-cell lung cancer. Clin Lung Cancer 2012; 13: 385-90. doi: 10.1016/j.cllc.2011.11.009

47. Park E, Park SY, Kim H, Sun PL, Jin Y, Cho SK, et al. Membranous Insulin-like Growth Factor-1 Receptor (IGF1R) Expression Is Predictive of Poor Prognosis in Patients with Epidermal Growth Factor Receptor (EGFR)-Mutant Lung Adenocarcinoma. J Pathol Transl Med 2015; 49: 382-8. doi: 10.4132/ jptm.2015.07.10

48. Zhao S, Qiu Z, He J, Li L, Li W. Insulin-like growth factor receptor 1 (IGF1R) expression and survival in non-small cell lung cancer patients: a meta-analysis. IntJ Clin Exp Pathol 2014; 7: 6694-704.

49. Richardson LC, Pollack LA. Therapy insight: Influence of type 2 diabetes on the development, treatment and outcomes of cancer. Nat Clin Pract Oncol 2005; 2: 48-53. doi: 10.1038/ncponc0062

50. Ding J, Tang J, Chen X, Men HT, Luo WX, Du Y, et al. Expression characteristics of proteins of the insulin-like growth factor axis in non-small cell lung cance patients with preexisting type 2 diabetes mellitus. Asian Pac J Cancer Prev 2013; 14: 5675-80.

51. LeRoith $D$, Roberts $C T$ Jr. The insulin-like growth factor system and cancer Cancer Lett 2003; 195: 127-37.
52. Wang HS, Wang TH. Polycystic ovary syndrome (PCOS), insulin resistance and insulin-like growth factors (IGfs)/IGF-binding proteins (IGFBPs). Chang Gung Med J 2003; 26: 540-53.

53. Zhou Y, Zhang X, Gu C, Xia J. Diabetes mellitus is associated with breast cancer: systematic review, meta-analysis, and in silico reproduction. Panminerva Med 2015; 57: 101-8.

54. Jiang $Y$, Ben $Q$, Shen $H$, Lu W, Zhang Y, Zhu J. Diabetes mellitus and incidence and mortality of colorectal cancer: a systematic review and meta-analysis of cohort studies. Eur J Epidemiol 2011; 26: 863-76. doi: 10.1007/s10654-0119617-y

55. Tian T, Zhang LQ, Ma XH, Zhou JN, Shen J. Diabetes mellitus and incidence and mortality of gastric cancer: a meta-analysis. Exp Clin Endocrinol Diabetes 2012; 120: 217-23. doi: 10.1055/s-0031-1297969

56. Walter U, Kohlert T, Rahbari NN, Weitz J, Welsch T. Impact of preoperative diabetes on long-term survival after curative resection of pancreatic adenocarcinoma: a systematic review and meta-analysis. Ann Surg Oncol 2014; 21: 1082-9. doi: 10.1245/s10434-013-3415-6

57. Wang YG, Wang P, Wang B, Fu Z, Zhao WJ, Yan SL. Diabetes mellitus and poorer prognosis in hepatocellular carcinoma: a systematic review and meta-analysis. PLoS One. 2014; 9: e95485. doi: 10.1371/journal.pone.0095485

58. Cai H, Xu Z, Xu T, Yu B, Zou Q. Diabetes mellitus is associated with elevated risk of mortality amongst patients with prostate cancer: a meta-analysis of 11 cohort studies. Diabetes Metab Res Rev 2015; 31: 336-43. doi: 10.1002/ dmrr.2582

59. Chen L, Li H, Gu L, MaX, LiX, Gao Y, et al. The impact of diabetes mellitus on renal cell carcinoma prognosis: a meta-analysis of cohort studies. Medicine (Baltimore) 2015; 94: e1055. doi: 10.1097/MD.0000000000001055

60. Jiamset I, Hanprasertpong J. Impact of diabetes mellitus on oncological outcomes after radical hysterectomy for early stage cervical cancer. J Gynecol Oncol 2016; 27: e28. doi: 10.3802/jgo.2016.27.e28

61. Inal A, Kaplan MA, Kucukoner M, Urakci Z, Kilinc F, Isikdogan A. Is diabetes mellitus a negative prognostic factor for the treatment of advanced nonsmall-cell lung cancer? Rev Port Pneumol 2014; 20: 62-8. doi: 10.1016/j. rppneu.2013.09.001

62. Hatlen P, Gronberg BH, Langhammer A, Carlsen SM, Amundsen T. Prolonged survival in patients with lung cancer with diabetes mellitus. J Thorac Oncol 2011: 6: 1810-7. doi: 10.1097/JTO.0b013e31822a75be

63. Imai H, Kaira K, Mori K, Ono A, Akamatsu H, Matsumoto S, et al. Prognostic significance of diabetes mellitus in locally advanced non-small cell lung cancer. BMC Cancer 2015; 15: 989. doi: 10.1186/s12885-015-2012-4

64. Zhu L, Cao H, Zhang T, Shen H, Dong W, Wang L, et al. The effect of diabetes mellitus on lung cancer prognosis: a PRISMA-compliant meta-analysis of cohort studies. Medicine (Baltimore) 2016; 95: e3528. doi: 10.1097/ MD.0000000000003528

65. Yin M, Zhou J, Gorak EJ, Quddus F. Metformin is associated with survival benefit in cancer patients with concurrent type 2 diabetes: a systematic review and meta-analysis. Oncologist 2013; 18: 1248-55. doi: 10.1634/theoncologist.2013-0111

66. Altman DG, McShane LM, Sauerbrei W, Taube SE. Reporting recommendations for tumor marker prognostic studies (REMARK): explanation and elaboration. PLoS Med 2012; 9: e1001216. doi: 10.1371/journal.pmed.1001216 